\title{
Reduced temperature and the chemical chaperone 4-phenylbutyrate enhance stability of 21-OHD mutations
}

\author{
Yiqing Chen ${ }^{1}$, Kerstin Schaefer ${ }^{1}$, Maria Gasteiger ${ }^{1}$, Angela Taylor ${ }^{3}$, Wiebke Arlt ${ }^{3}$, Nils Krone ${ }^{4}$, Soeren Gersting ${ }^{2}$, Nicole Reisch ${ }^{1}$ \\ 1 Department of Endocrinology, Medizinische Klinik und Poliklinik IV, Klinikum der Universität München, München \\ 2 Department of Molecular Pediatrics, Dr. von Haunersches Kinderspital, Klinikum der Universität München, München \\ 4 Academic Unit of Child Health, Department of Oncology and Metabolism, University of Sheffield, UK
}

\section{Introduction}

Congenital adrenal hyperplasia (CAH) is one of the most common autosomal recessive metabolic disorders characterized by a complex imbalance of adrenal steroids. The most common form, 21hydroxylase deficiency (21-OHD) due to CYP21A2 mutations accounts for more than $90 \%$ of all cases of CAH and constitutes a life-threatening disease. The current therapeutic situation is unsatisfying and demands novel treatment approaches. In silico modelling suggests protein misfolding and intracellular retention to play a significant role in the pathogenesis of CAH. The study aimed to investigate protein misfolding due to CYP21A2 mutations and explore chemical chaperones as potential therapeutic tools for CYP21A2 mutants.

\section{Methods and materials}

Clinically relevant CYP21A2 mutations where in silico modelling suggested protein misfolding to play a role in the pathogenesis of CAH were selected and subcloned into pcDNA6-V5/His expressing vectors. Residual activity of variant CYP21A2 proteins was determined in living cells using an enzyme activity assay with LC/MSMS based analysis of steroids. The effect of mutations on protein half-life (susceptibility to proteinase $K$ ) was measured comparing wild-type and variant CYP21A2. The influence of 4-phynylbutyrate (4-PBA) and reduced temperature on protein half-life was investigated.

(1)

Results

\begin{tabular}{|c|c|c|}
\hline Mutation & Mean $(\mathbf{m i n})$ & SEM \\
\hline WT & 8.35 & 0.62 \\
\hline P30L & 1.40 & 0.04 \\
\hline P30Q & 1.00 & 0.07 \\
\hline G90V & 0.95 & 0.17 \\
\hline R483Q & 2.37 & 0.05 \\
\hline R483W & 0.93 & 0.09 \\
\hline
\end{tabular}

Table 1. Half-life of wild-type (WT) and variants CYP21A2 at $37^{\circ} \mathrm{C}$. Degradation of the WT and mutant proteins were probed by western-blotting analyses. Densitometric analysis was performed using Imagequant software. The calculated half-life of WT and mutations are given in mean \pm SEM of $n=3$ independent experiments.

Compared with WT, all mutations showed reduced half-life, indicating that CYP21A2 mutations caused protein instability.

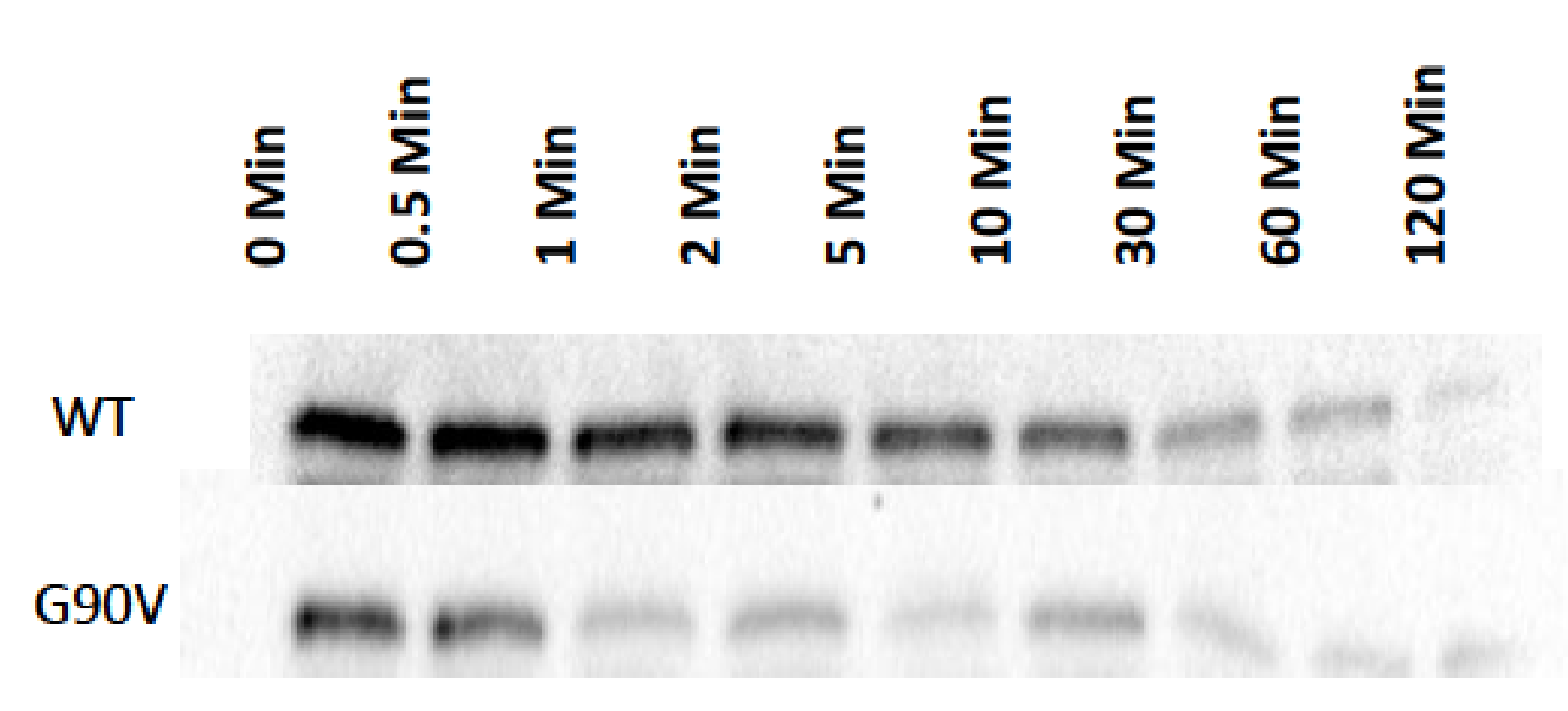

B

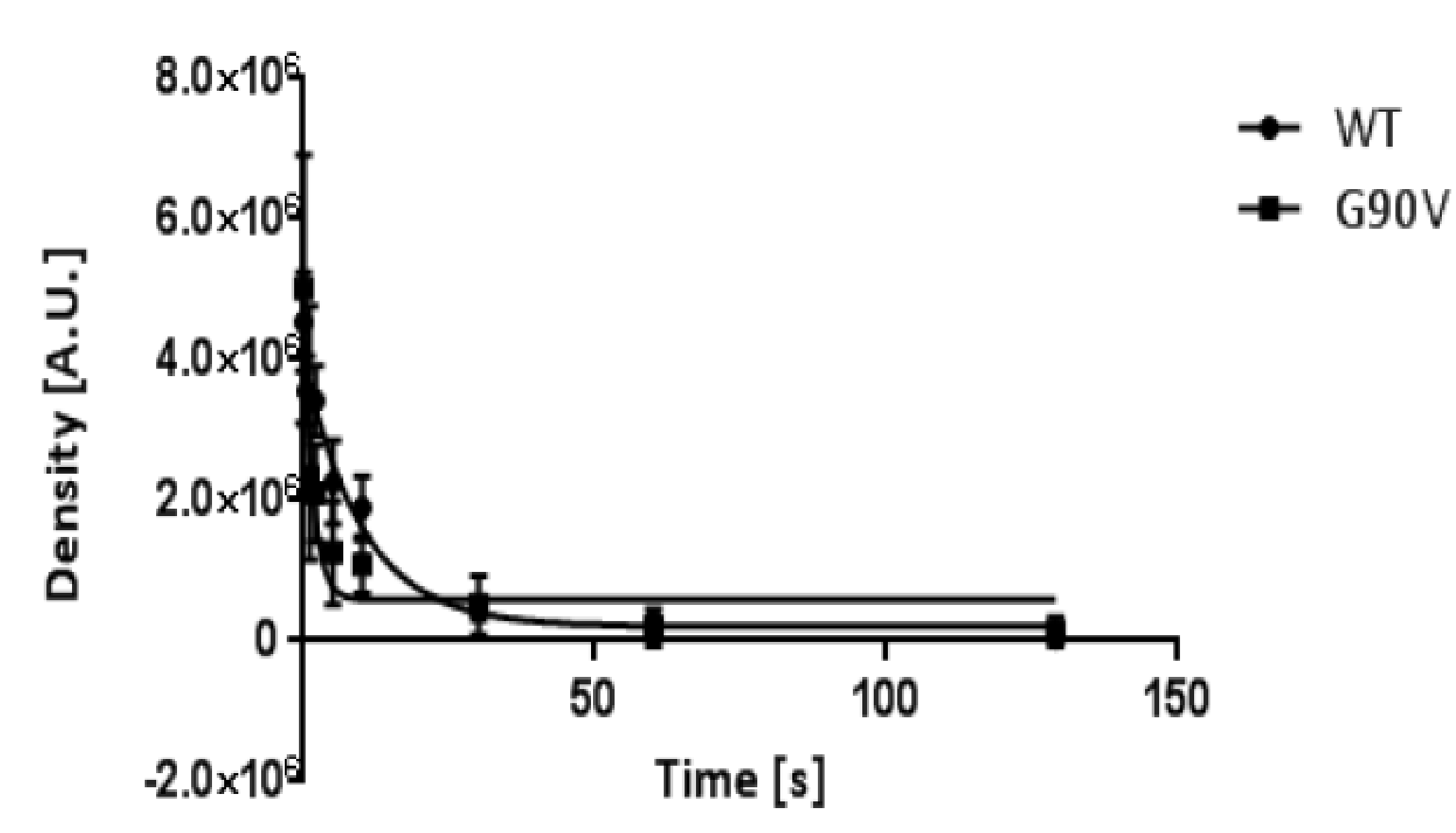

Figure.1 A. Representative Western blot images of WT and G90V against limited proteolysis by Proteinase $\mathrm{K}$ at $37^{\circ} \mathrm{C}$. B. Degradation curve of WT and G90V according to densitometric analysis of each time point. The value of each time point is given in mean $\pm S E M$ of $n=3$ independent experiments.

WT showed a longer half-life because of the lowest rate of degradation. In contrast, G90V had a rapid decay rate compared with WT so that the half-life was much shorter.

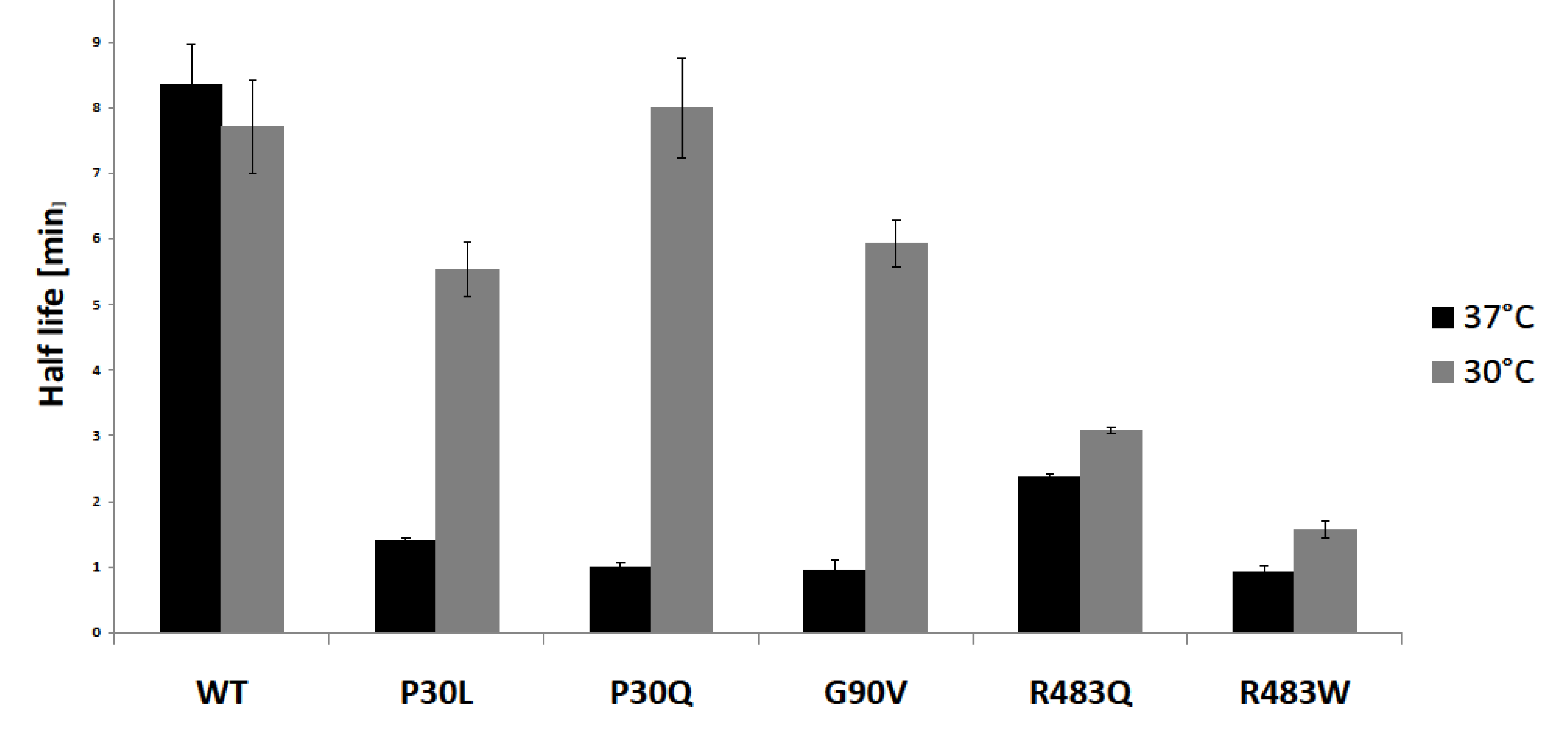

Figure.2 Half-life of WT and mutant proteins at $37^{\circ} \mathrm{C}$ and $30^{\circ} \mathrm{C}$. Half-life determinations were from three independent experiments at $37^{\circ} \mathrm{C}$ and $30^{\circ} \mathrm{C}$. The bar graph represents mean $\pm \mathrm{SEM}$.

The half-life of WT at $37^{\circ} \mathrm{C}$ and $30^{\circ} \mathrm{C}$ did not show any difference, while $30^{\circ} \mathrm{C}$ enhanced half life of all tested mutants.

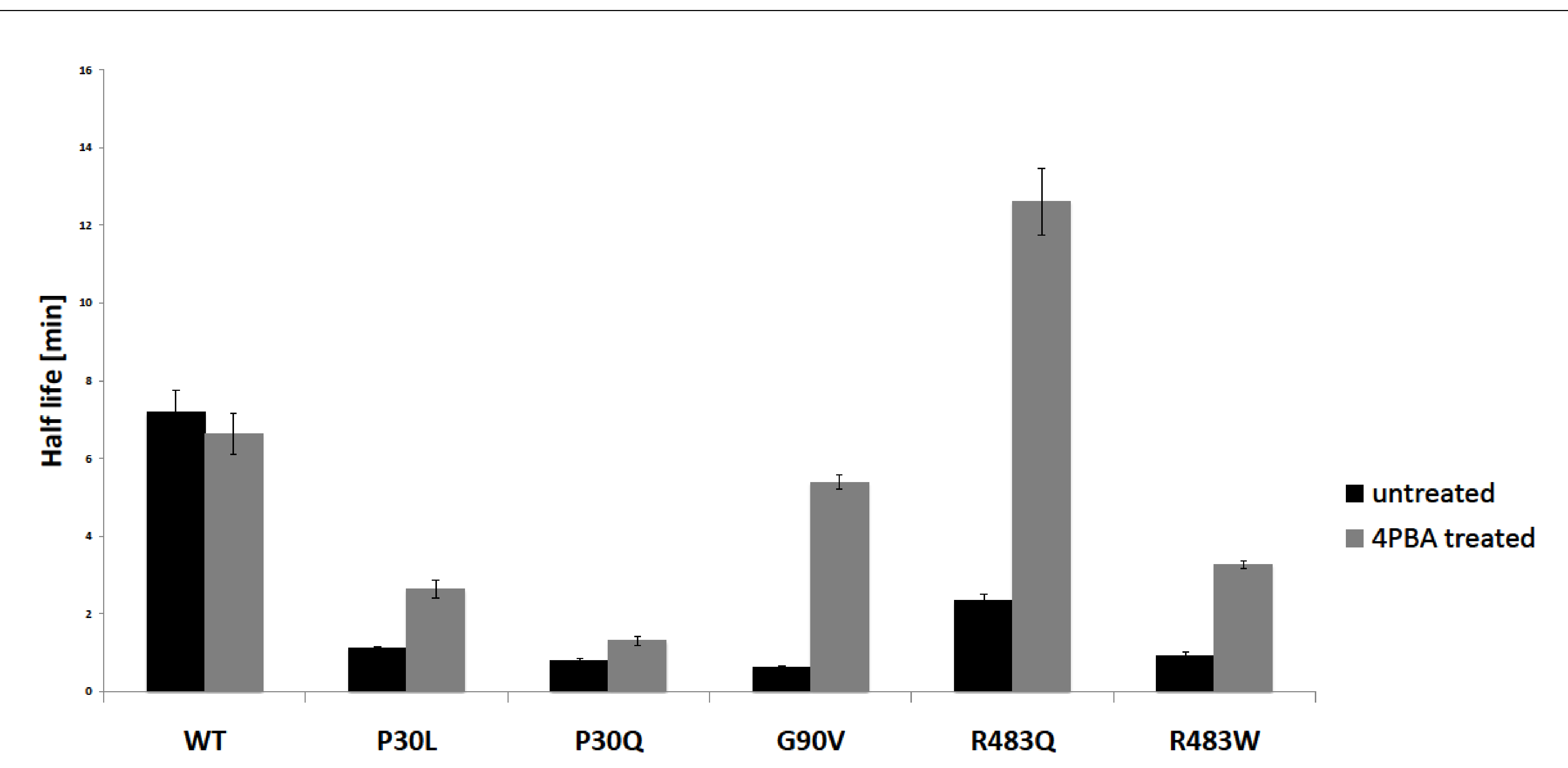

Figure.3 Half-life of WT and mutation proteins with and without 4PBA treatment. Cells were cultured with or without the presence 4PBA $(1 \mathrm{mM})$ for $24 \mathrm{~h}$ before the protein extraction and western-blotting. Each value represents mean \pm SD of three independent experiments performed. There was no difference of the half-life of WT with and without 4PBA treatment. After treatment, decreased susceptibility to proteinae $K$ was observed compared with half-life of untreated proteins in all mutations.

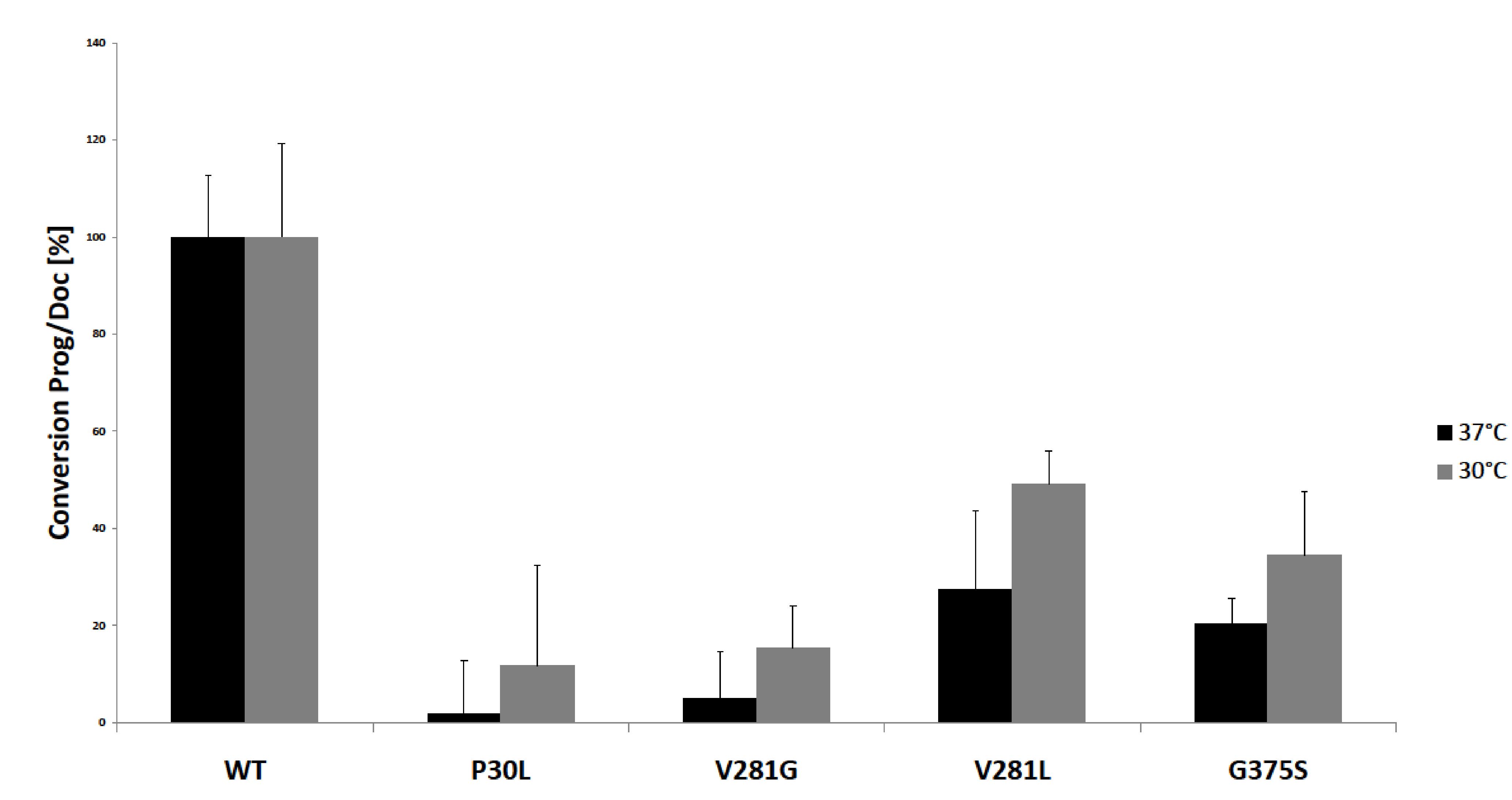

Figure.4 Residual 21-hydroxylase activity of the CYP21A2 mutants in transiently transfected cOS7 cells at $37^{\circ} \mathrm{C}$ and $30^{\circ} \mathrm{C}$. The activity of the mutants was expressed in percentage of WT activity, which was defined as $100 \%$. Values were depicted for the conversion of progesterone to deoxycorticosterone at a substrate concentration of $200 \mathrm{nM}$ of unlabeled steroid (time of incubation $2 \mathrm{~h}$ for $37^{\circ} \mathrm{C}$ and $8 \mathrm{~h}$ for $30^{\circ} \mathrm{C}$ ). The bars represent the mean \pm SEM for three different and independent transfections for WT and each mutant.

The results showed that all mutations displayed significantly reduced in vitro enzyme activities compared with WT enzyme in $37^{\circ} \mathrm{C}$. However, there was a marked increase in activity of all mutations at $30^{\circ} \mathrm{C}$.

\section{Conclusion}

Our preliminary data substantiate the hypothesis of protein misfolding with loss-of-function as a relevant molecular mechanism in CAH that can be addressed by structural stabilisation of CYP21A2. These strategies above may provide new avenues in 21-OHD treatment.

\section{References}

1. Merke, D. P., \& Bornstein, S. R. (2005). Congenital adrenal hyperplasia. The Lancet, 365(9477), 2125-2136. doi: 10.1016/s0140-6736(05)66736-0.

2. Robben, J. H., Sze, M., Knoers, N. V. A. M., \& Deen, P. M. T. (2006). Rescue of vasopressin V2 receptor mutants by chemical chaperones: specificity and mechanism. Mol Biol Cell, 17(1), 379-386. doi: 10.1091/mbc.E05-06-0579

3. Burrows, J. A., Willis, L. K., \& Perlmutter, D. H. (2000). Chemical chaperones mediate increased secretion of mutant alpha 1-antitrypsin (alpha 1-AT) Z: A potential pharmacological strategy for prevention of liver injury and emphysema in alpha 1-AT deficiency. Proc Natl Acad Sci U S A, 97(4), 1796-1801. 